\title{
Developing a novel approach for modeling the social effects of technology transfer
}

\author{
Ali Reza Moini, Ali Reza Babakhan* and Ali Esmaieeli
}

Department of Industrial Engineering, Iran University of Science \& Technology, Tehran, Iran

\begin{tabular}{l}
\hline A R T I C L E I N F O \\
\hline Article history: \\
Received October 1, 2011 \\
Received in Revised form \\
November, 14, 2011 \\
Accepted 30 January 2012 \\
Available online \\
20 February 2012 \\
\hline Keywords: \\
Technology Management \\
Technology Transfer \\
Social Development \\
Dynamic System
\end{tabular}
A B S T R A C T

\begin{abstract}
Nowadays technology transfer is considered as the process of sharing skills, expertise, knowledge and technologies either among government and institutions or between transferee and transferor enterprises. Using scientific investigations and real-world instances of practice, this study tries to show the importance of technology transfer and its role in societal development. Applying the views of the related literature and using a dynamic system approach and experts' opinions, this study is supposed to determine positive and negative relations among different components of social development and technology transfer which are namely the parts of technological give and takes.
\end{abstract}

\section{Introduction}

In practice, technology is the know-how which modifies the ability of an organization in order to create a product or a service (Sung, 2009). Technology transfer (TT) is defined as any process that moves the basic understanding, information and innovations from a university, research institution or a civil laboratory to individuals and corporations in the private and quasi-private sectors (Pedro et al., 2009). In the current situation, where technologies seem to be countless, it would be appropriate to introduce Technology Transfer Management (TTM) (Sung, 2009), which contains a group of processes. The processes should be started from the needs analysis of the recipient and determination of the feasibility of technology acquisition, then appropriate technologies which meet the needs well, should be selected in the next stage. After the selection of candidate technology for transferring, appropriate transfer channels should also be selected. Negotiation and contracting; technology acquisition; technology adaption, and technology development are the following stages of a logical and well-developed pattern for the cultivation of the received technology (Ale Ebrahim et al., 2009; Ayres, 1988).

One of the important considerations in fulfillment of the needs of the users is attention to changes in the settings of the new technologies. Information that is received in this regard can provide the

* Corresponding author. Tel: +912 5521400

E-mail addresses: alibabakhan1990@gmail.com (A. Babakhan) 
opportunities to have access to new processes, techniques, and key competencies, which will contribute to innovations in production, marketing, management and accounting (De La Tour et al., 2011). Using new technologies, entities can overcome problems and compete with larger enterprises (Xiaolan, 2011). To globalize and diversify their processes, companies also make use of technology transfer (Hübler, 2011). TT has exhibited positive influences on the information exchange among different companies and enhancement of their abilities to adapt with different situations (Parker \& Zilberman, 1993). The above mentioned benefits will be gained if and only if, useful technologies and appropriate strategies are selected and the TT process is understood by companies (Tetsunori \& Kenneth, 1980). TT projects have high risk potentials that would not guarantee well return investment or prosperous production (Dorf \& Worthington, 1990; Eldred \& McGrath, 1997a,b; Siegel et al., 2004; Çetinel et al., 2004). From an academic point of view, TT is interpreted as the process of conveying and exchange of ideas, innovations and discoveries outside of the research laboratory, and the commercial sector (Crespi et al., 2011; Caldera \& Debande, 2010; Jackson et al., 2010; Link et al., 2011). The pure effects of this type of technology transfer can be seen in creation of new products, development of companies, increase in employment, and taxes which provides the situation for further development of economy (United Nations, 2006).

In recent years, TT issues have been attended seriously in Iranian context. One of the important considerations in TT is attention to its positive and negative social impacts. In other words, policy makers should have considerations of the effects of technology transfer on different parts of the society. They should apply their knowledge concerning how and when technology transfer can influence the society in their decisions (Hoekman et al., 2005). The gap that is felt because of the lack of a systematic model is decided to be filled by applying a dynamic system model accompanied with its components affecting society in this paper.

\subsection{Benefits of Technology}

TT strengthens industries by identification of new business opportunities for those who are responsible for providing different types of technologies and systems (Chen \& Sun, 2000). This effect can enhance the expertise of the related staff that leads them to broaden the area of their business and consider applications of their technologies and systems in other fields. In addition, TT promotes awareness and wider use of technologies and systems. Although some spin-offs and projects do not necessarily have immediate and tangible social and health benefits, they may have some safety benefits in specialized sectors. There are some other benefits for TT that are less obvious such as:

- The ability to decrease the burden of research and development which have been imposed on public resources, by adapting developed technologies, systems and competencies for applications in different sectors (Henry et al., 2009).

- Providing cross-disciplinary opportunities for researchers to collaborate with other organizations (Brown \& Flynn, 2002; Anna \& Maria, 2010; Niina, 2003).

- Providing economic potential and motivation for technology donors and technology receivers in the settings with high social impact and high potential market (De La Tour et al., 2011).

Some economic benefits associated with the application of TT can also be the result of increase in revenues of donors and receivers of technology (Meheroo, 1980). TT as the process concerning the exchange of scientific information among organizations for their further development and commercialization includes the following steps (Jackson et al., 2010):

1. Identification of new technologies

2. Protection of technologies using patents and copyrights

3. Formation of strategies for development and commercialization such as marketing, licensing private sector companies, and creating new start-ups based on technology

Academic and research institutions apply TT for a variety of reasons, including: 
- Recognition of the discoveries performed in the institutions

- Compliance with predetermined national regulations

- Attraction and retention of potential sections

- Development of local economics

- Attraction of supports for research corporations

- Licensing revenues to support further research and education

Patents that are provided by academic institutions support opportunities for research discoveries (Albert et al., 2011). The results of investments on new ideas are increase in the numbers of new corporations, proliferation of products which are at the service of the population, increase in the employment, and growth of state and federal taxes. Increases in the numbers and sizes of organizations are meant a raise in the number of required technologies which can contribute to performing more research projects. The trust of industry sector in the capabilities of higher education institutes leads to the increase in the number of assigned research projects to universities; improvement of the capabilities of universities staffs and students in changing their learnt theories into practice and an acceptable connection between industry sectors and higher education institutes. These benefits can be resulted without any problems regarding public values, information sharing, research findings, materials and competencies (Rory et al., 2005).

In the recent decades, there has been considerable attention to TT by higher degree educational institutes and industries (MacBryde, 1997; Mian, 1994; Liyanage \& Mitchell, 1994). Due to the increase in the traditional teaching missionaries, research, public services, a dramatic change has been observed in the high degree educational institutions of some countries such as USA, UK, Germany, France and Japan, since the early 1980s. This change has played an active role in the economic growth of such countries (Main, 1997). The more academic institutions are focused, the more complicated relationships, interactions and expectations are resulted for economic development (Donald et al., 2004). Various forms of Industry-University corporations (D'Este \& Patel, 2007) are the focal tools of regional development, because they use required scientific knowledge for providing business. These connections allow corporations to utilize skilled proficiencies and technical supports and to have access to vital facilities for their R\&D activity (Grossman et al., 2001).

\section{The role of technology}

At present time, inability to identify, develop, and apply appropriate technologies in production is considered as a major cause for slow progress of social, economic and cultural advancements of the developing countries (Nazmun et al., 2006). Due to this fact, developing countries are paying increasing attention to efficient management of technology. The processes of technological assessment, acquisition, forecasting and diffusion are some examples of the tools which can build a road to technological developments (Janssen, 2010). In fact, technologists, engineers, scientists, policy makers, etc. are in need of the referred tools and strategies for decision making and implementation processes.

Economic progress of countries, industries, and businesses depends on the appropriate management of technology. Advancement in technology results in the improvement of industrial performances, which implies appropriate use of energy and finance; industrial efficiency; and an increase in profits (Bernard et al., 2005; O'Shea et al., 2005). The proper exploitation of technology strongly influences business competition, which is no longer a matter of choice, but a matter of survival in the marketplace (Pedro et al., 2009). Private firms and organizations acknowledge a link between innovation and economic success at macro and micro levels (Xiaolan, 2011). The application of technology is obviously beneficial for technological development, success in the global competitive economy and an increase in the market shares (Tetsunori \& Kenneth, 1980; United Nations, 2006). One of undeniable factors in this regard is the education of human sources needed for the everchanging technological organizations (Khalil, 2000; Camilla \& Sucharita, 2009). This factor depends 
on the abilities of the leaders in management of the resources in the rapidly changing world of technology.

\subsection{Bases of TT}

It is worth to consider some issues regarding the process and application of TT. Such considerations can be the bases for the success and prosperity of TT. They have been summarized as follows:

1. Situational services and production sectors as the main investors of new technologies:

- Sector as a component, its size, economical power, its local and international status; and its growth rate (Nazmun et al., 2006; Jason, 1992).

- The availability of the sources required to acquire basic materials and components that support technological investments (Barry \& Patrick, 2002).

2. The supporting infrastructure (Manuel, 2009; Ann \& Juan, 2000):

- The availability of local parties specialized in issues such as technical support, preventive measures and centers specialized in research and development.

3. The norms of the working sector and their availability to accept, and utilize new technologies:

- Enough experiences in people (Jess \& Mark, 2005) and technical capitals to exploit new technologies.

- The deep acquisition of scientific and technological knowledge that can lead to appropriate modification and proper use of technologies by receiving parties (Michael et al, 2000).

4. Existing laws, legislations, and the institutes that are concerned with investment in TT for the purposes of control and guidance (King \& Nowack, 2003):

- Development of projects for utilization of new technologies

- Importing required materials and investments

- Taxation and duty systems

- Issues such as people, their cultures, and the relationships among related parties, public and private sectors (Janssen, 2010)

5. International considerations:

- Transfer and acquisition of technology; prohibition of the exportation of technology and equipments by some advanced countries (Kym, 1989).

6. Negotiations among countries to break certain prohibitions to be able to bring mutual benefits and form unions that can develop science and technology (Shafia \& Shakeri, 2010).

Most of the effects of TT have been referred to so far, but there is a question asked by developing countries concerning the way TT can affect society. The answer which has been provided in this article is that the use of a dynamic system approach can provide a link among social parameters which affect each other by TT.

\subsection{The Role of Government in Developing TT for Economic Transformation}

TT involves the conversion of ideas into useful inventions which leads to the development of marketable products and processes (Caldera \& Debande, 2010). This process occurs at the interface of the commercial world where all players make time trade-offs and use resources for commercial gain (Jackson et al, 2010). This implies that sometimes people act in isolation and without full knowledge of total conditions. Consequently the government and private sectors have the responsibility to set the following components of TT (Manuel, 2009; Jackson, 2010):

- $\quad$ The scale and scope of research infrastructure

- The motivations of researchers in developing ideas for commercialization

- The interactions of researchers and people who invest in innovations and can take an acceptable level of commercial risk 


\subsection{Collaboration and communication between local and international R \& Ds}

The success of any technological effort in solving the research questions is very much related to the availability of different types of internal and external organizational networks. In the past, there has been a limited collaboration between national and regional organizations, but the collaborations between local and international organizations have been active and productive. The first step to be followed in an enterprise is to acquire new technologies for the improvement of competitive performance accompanying innovation. However, the ultimate performance depends on the power of the enterprise in effective management of new technologies for successful adaption of technology. The activities that can be critical in this regard include training, marketing, and investment (Anna \& Maria, 2010). Mobile Corporation includes training and communication is an example of TT inside an organization. Similar to Mobile Corporation, other enterprises can conduct internal training of TT programs that facilitate the application of TT within the organizations and adaptation of new technologies outside of the organizations. Enterprises must develop strategic cohesions in all aspects of their innovations (Dodgson, 1991). In situations where the enterprises must obtain technological resources from external resources such as public institutions, larger corporations, and subsidiaries, the success of technological venture depends on the power of that enterprise in organizing and managing cooperative relationships (Niina, 2003).

\section{System dynamics modeling}

System dynamics can be considered as particular approaches in the general system theory. As Bertalanffy (1974) states, general system theory is a 'logico-mathematical field reflecting the quest for rigor in the deduction and confirmation of its theories' (Bertalanffy, 1968). Also, as Adams (1981) said 'if science were to go on doubling or quadrupling its complexities every 10 years, even mathematics should soon succumb. An average mind had succumbed already in 1980; it could no longer understand the problem in 1900' (Adams, 1981). The dynamics of a system are hard sciences that consist of a group of variables including a lot of interactions with their environment and among themselves. These interactions can be tested using a series of differential equations. However, theses approaches cannot be sufficient for understanding the behaviors of complex systems. Hierarchy of systems, the social systems and the transcendental systems are at the same levels of complexity (Albert et al., 2011). If we consider the cognitive limitations of human brain, each time human beings can comprehend only three dimensions of a seven dimensional phenomenon (Miller, 1956). If the number of dimensions becomes more than three, human comprehension will encounter problems and lacks of capacity (Warfield, 1990). For this reason, System Dynamics (SD) is an appropriate approach to deal with complex social systems. Forrester developed SD with the power to stimulate large-scale systems and to solve their problems, by means of integrating system theory, cybernetics, information theory and computer technology (Jay, 1973). SD has been made of dynamic stimulation models accompanying informative feedbacks to control the target system's interactions. SD can acquire more detailed information using developmental trends and diagnosing the interconnections and feedbacks in each of the factors of that system. This process can help to recognize the unknown behaviors and the total proficiency of the system (Wang, 1994). SD has been used in scientific fields such as strategic planning, supply chain, software development and project management (Georgiadis et al., 2005; Dyner \& Smith, 1995; Rodrigues \& Williams, 1998). There are a lot of factors that can affect TT projects. These factors have many linkages and interactions that make a strong connection between TT projects and its environment. Considering all of these interactions, using system dynamics is the best way to show the connections of all these factors.

\subsection{Causal Loop Diagrams}

The main purpose of causal loop diagrams (CLDs) is showing the feedback structure of the system. CLDs are beneficial for: 
- Rapid development of your assumptions on the causes of dynamics

- Development of mental models of an individual or a group of people

- Making connections among the feedbacks for the problems

A CLD consists of variables which are connected to each other using the arrows that show the causal relationships among the variables. Each arrow has a polarity that shows the ways that the dependent variable changes. Positive and negative identifiers in loops refer to reinforcement and balancing, respectively.

\subsection{Integration of Important and Effective Factors in TT}

In Table 1, all the influential variables and factors in TT which are referred to in this paper, have been gathered:

\section{Table 1}

Integration of effective variables in TT which have been mentioned in this paper

\begin{tabular}{lll}
\hline Num & Variables & References \\
\hline 1 & $\begin{array}{l}\text { Economic motivation for both technology donors and } \\
\text { receivers }\end{array}$ & (Meheroo, 1980) \\
\hline 2 & Patenting & (Albert, 2011) \\
\hline 3 & Size of investor organizations & (Nazmun et al., 2006; Jason, 1992) \\
\hline 4 & The ability to identify the right technology to obtain & (Nazmun et al., 2006) \\
\hline 5 & Profitability & (Bernard et al., 2005) \\
\hline 6 & Efficiency & (Bernard et al., 2005) \\
\hline 7 & Utilization of energy and money & (Bernard et al., 2005) \\
\hline 8 & Performance of the industry & (Bernard et al., 2005) \\
\hline 9 & Competitiveness & (Pedro, 2009; Tetsunori \& Kenneth, 1980; United \\
& & Nations, 2006) \\
\hline 10 & Market share & (Pedro, 2009; Tetsunori \& Kenneth, 1980; United \\
& Nations, 2006) \\
\hline 11 & Investment in human and knowledge capital & (Khalil, 2000) \\
\hline 12 & Economical strength of the organizations and government & (Nazmun et al., 2006; Jason, 1992) \\
\hline 13 & The availability of needed resources as the supporters of & (Barry \& Patrick, 2002) \\
\hline 14 & investment in technologies & \\
\hline 15 & Availability of local parties to provide technical supports & (Manuel, 2009; Ann \& Juan, 2000) \\
\hline 16 & Nhe background of human and technical capital & (Jess \& Mark, 2005; Manuel, 2009) \\
\hline 17 & Commercialization of ideas & (Shafia \& Shakeri, 2010) \\
\hline
\end{tabular}

Table 2

The missing factors added through arguing with experts

\begin{tabular}{|c|c|c|c|}
\hline Num & Variables & Num & Variables \\
\hline 1 & Transference of new technologies to universities & 11 & Number of corporations \\
\hline 2 & Budget assigned to technology transfer projects & 12 & Employment \\
\hline 3 & Resistance against new technologies & 13 & Gaining from taxes \\
\hline 4 & Connection to other universities in the world & 14 & Number of researches \\
\hline 5 & $\begin{array}{l}\text { Scientific conferences and meetings between } \\
\text { higher education institutes and industry }\end{array}$ & 15 & Transference of research projects to universities \\
\hline 6 & $\begin{array}{l}\text { The scientific advancement rate of higher } \\
\text { education institutes }\end{array}$ & 16 & Trust of the industry to higher education \\
\hline 7 & $\begin{array}{l}\text { Dispatching collegian abroad for training and } \\
\text { transferring technologies }\end{array}$ & 17 & $\begin{array}{l}\text { The capabilities of university teachers and students in } \\
\text { transforming academic learning into practice }\end{array}$ \\
\hline 8 & $\begin{array}{l}\text { The relation between higher education institutes } \\
\text { and industry }\end{array}$ & 18 & $\begin{array}{l}\text { Transforming of experiences and problems of industry } \\
\text { to academics }\end{array}$ \\
\hline 9 & $\begin{array}{l}\text { Trust of the industry sector to effectiveness of the } \\
\text { technology transfer process }\end{array}$ & 19 & $\begin{array}{l}\text { Knowledge transference of the higher education } \\
\text { institutes to industry sector }\end{array}$ \\
\hline 10 & Investment on intellectual property & 20 & $\begin{array}{l}\text { Communication between R\&D locally and } \\
\text { internationally }\end{array}$ \\
\hline
\end{tabular}


To indicate the relations and correlations of these variables, a model is needed. Experts have selected System Dynamics to be the best model in this regard. However, after modeling, some of the loops were seemed to be incomplete. This problem was solved through the discussions among experts. At the end, by consideration of the effective factors in TT, some of the missing factors were found and added to the model. These factors have been referred to in Table 2.

\subsection{Causal Relationship Diagram of Social Effects of TT}

Fig. 1 indicates the causal relations among the influential variables of TT in society. Because of the existence of many loops in this diagram, just the important loops are described. The other loops can be understood following the provided examples.

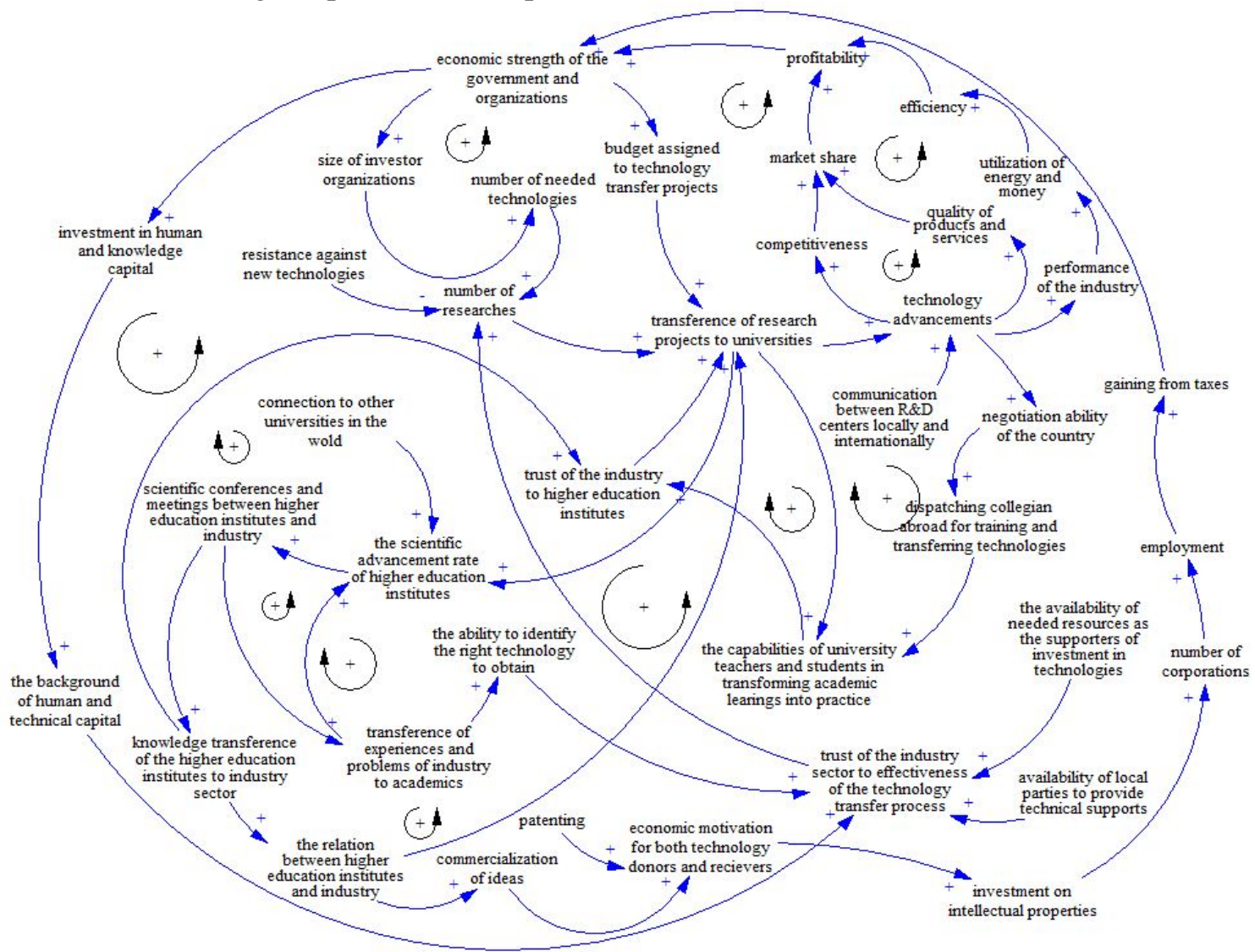

Fig. 1. Casual loop diagram of social effects of TT

Loop 1: advancement of technology will cause an increase in the quality of products and services which can lead to greater market share and more profitability. More profitability can be defined as more economic power of the organizations and governments and can increase the size of investor organizations. The increase in the size of investor organizations leads to an increase in the amount of technologies and number of researchers. Subsequently, an increase in the number of researchers can lead to an increase in the transference of research projects to universities and advancement in technology.

Loop 2: as investment on intellectual properties increases, the number of corporations which work based on these new ideas will be increased. This can lead to a decrease in unemployment and as a result an increase in gaining taxes as one of the goals of government for increasing economic power. The strength of the government and organizations as its building blocks can cause an increase in technological investments. Technological investments can lead to the growth of technologies and the achievement of the aims of organizations. Increase in the number of researchers as a result of increase 
in required technologies can cause an increase in the transference of research projects to universities, trigger the advancement of higher education institutes and as a result, an increase in the numbers of conferences and meetings which are held between universities and industries. Knowledge transference and familiarity with each others' capabilities among the referred sectors can develop successful connections, identification of good ideas and investment on these ideas. Commercialization of good ideas increases economic motivations. All of the described issues can have impacts on the increase of intellectual properties and can make this loop to go on in an iterative manner.

Loop 3: the performance of industry will be increased through advancement in technology which results in more appropriate consumption of energy and finance, more efficiency in the whole industry, more profitability, economic strength of the government, richness of technical capital, more trust in the effectiveness of TT in industry, an increase in the number of researchers, and advancement of technology. It is understood that this loop and all other loops act in a way that the results will be the same. Therefore understanding the activities that are followed in other loops seems to be obvious.

\section{Conclusion}

This paper discussed the idea of TT, its goal, its strategies, and its effects on social progress from different perspectives. It is believed that TT is influential for developing economies which are densely populated. System thinking seems to be the best way for acquisition of proper perception of the real impacts of TT on society, and its components including higher education institutes, law and industry. An upsurge in the number of technological corporations, employment and taxes and a decrease in the wastes of energy and resources would occur. All of these effects can develop a more appropriate level of living in the society.

The SD model was introduced to experts and had been approved to be correct. By means of this systematic thinking, the process TT can be managed much more efficient by the government and the policy makers, and also the industry sector would experience an upsurge in the level of technology which helps them to compete with the other participates in today's contest of advancement. Also an upsurge in the number of technology based corporations, employment and taxes and decrease in waste of energy and material would be occurred and all of these effects will guide to a better society and higher level of human being's living.

\section{References}

Adams, H. (1981). The Education of Henry Adams. Boston: Houghton-Mifflin.

Ale Ebrahim, N., Shafia, M. A., \& Tahbaz Tavakoli, H. (2009). Virtual R\&D team: Technology Transfer Facilitator. The 18th International Conference on Management of Technology, Orlando, Florida, USA.

Ann, C. S., \& Juan, M. F. A. (2000). Telecommunications technology transfer and the development of institutional infrastructure: the case of Cuba. Telecommunications Policy, 24(3), 203-221.

Anna, B., \& Maria, B. (2010). Are patents with multiple inventors from different countries a good indication of international R\&D collaboration? The case of ABB. Research Policy, 39(10), 13211334.

Ayres, R.U. (1988). Technology: The wealth of nations. Technological Forecasting and Social Change, 33(3), 189-201.

Brown, B. S., \& Flynn, P. M. (2002). The federal role in drug abuse technology transfer: a history and perspective. Journal of Substance Abuse Treatment, 22(4), 245-257.

Bertalanffy, L. (1968). General Systems Theory. Foundations, Development, Applications. New York, George Braziller, von.

Caldera, A., \& Debande, O. (2010). Performance of Spanish universities in technology transfer: An empirical analysis. Research Policy, 39(9), 1160-1173. 
Chen, X., \& Sun, C. (2000). Technology transfer to China: alliances of Chinese enterprises with western technology exporters. Technovation, 20(7), 353-362.

Crespi, G., D'Este, P., Fontana, R., Geuna, A. (2011). The impact of academic patenting on university research and its transfer. Research Policy, 40(1), 55-68.

Çetinel, F., Yolal, M., \& Emeksiz, M. (2004). Managing human resources in small organizations: What do we know? Human Resource Management Review, 14(3), 295-323.

King, D.R., \& Nowack, M.L. (2003). The impact of government policy on technology transfer: an aircraft industry case study. Journal of Engineering and Technology Management, 20(4), 303-318.

De La Tour, A., Glachant, M., \& Meniere, Y. (2011). Innovation and international technology transfer: The case of the Chinese photovoltaic industry. Energy Policy, 39 (2), 761-770.

D'Este, P., \& Patel, P. (2007). University-industry linkages in the UK: What are the factors underlying the variety of interactions with industry? Research Policy, 36, 1295-1313.

Dodgson, M. (1991). The Management of Technological Learning. Berlin: De Gruyter.

Dorf, R.C., \& Worthington, K. K. F. (1990). Technology transfer from universities and research laboratories. Technology Forecasting and Social Change, 37, 251-266.

Dyner, I., Smith, R.A., \& Peña, G.E. (1995). System dynamics modeling for residential energy efficiency analysis and management, Journal of Operational Research Society, 46, 1163-1173.

Eldred, E. W., \& McGrath, M. E. (1997). Commercializing new technology- I. Research • Technology Management, 41-47.

Eldred, E.W., \& McGrath, M.E. (1997). Commercializing new technology — II. Research • Technology Management, 29-33.

Georgiadis P., Vlachos D., \& Iakovo E. (2005). A system dynamics modeling framework for the strategic supply chain management of food chains. Journal of Food Engineering, 70, 351-364.

Grossman, J. H., Reid, P. P., \& Morgan, R. P. (2001). Contributions of academic research to industrial performance in five industry sectors. The Journal of Technology Transfer, 26(1-2), 143152.

Henry, M., Kneller, R. \& Milner, C. (2009). Trade, technology transfer and national efficiency in developing countries. European Economic Review, 53(2), 237-254.

Hoekman, B. M., Maskus, K.E., \& Saggi, K. (2005). Transfer of technology to developing countries: Unilateral and multilateral policy options. World Development, 33(10), 1587-1602.

Hübler, M. (2011). Technology diffusion under contraction and convergence: A CGE analysis of China. Energy Economics, 33(1), 131-142.

Jackson, M. J., Whitt, M.D., Handy, R.G., Robinson, G.M., \& Whitfield, M.D. (2010). Commercialization of Nanotechnologies: Technology Transfer from Universities Research Laboratories. Emerging Nanotechnologies for Manufacturing, 251-260.

Janssen, R. L. (2010). Exploring the impact of culture: Technology transfer to five African countries. Master Thesis, University of Twente, the Netherlands.

Jason, Z. Y. (1992). Technological capabilities as determinants of the success of technology transfer projects. Technological Forecasting and Social Change, 42(1), 17-29.

Jay, F. (1973). World Dynamics. MA: Wright-Allen Press.

Jess, B., \& Mark, M. S. (2005). Chapter 13 Human Capital and Technology Diffusion. Handbook of Economic Growth, 1(1), 935-966.

Jussawalla, M. (1980). Communication technology transfer: Impact on economic development. Telecommunications Policy, 4(4), 249-262.

Khalil, T. M. (2000). Management of Technology: The Key to Competitiveness and Wealth Creation, 343, McGraw Hill.

Kym, A. (1989). Does agricultural growth in poor countries harm agricultural - exporting rich countries? Agricultural Economics, 3(4), 309-321.

Laranja, M. (2009). The development of technology infrastructure in Portugal and the need to pull innovation using proactive intermediation policies. Technovation, 29(1), 23-34. 
Lengnick-Hall, C.A., Lengnick-Hall, M.L., \& Abdinnour-Helm, S. (2000). Technological learning, knowledge management, firm growth and performance: an introductory essay. Journal of Engineering and Technology Management, 17(3-4), 231-246.

Link, A.N., Siegel, D.S., \& Van Fleet, D.D. (2011). Public science and public innovation: Assesing the relationship between patenting at U.S. National Laboratories and the Bayh-Dole Act. Research Policy, 40(8), 1094-1099, 2011.

Liyanage, S., \& Mitchell, H. (1994). Strategic management of interactions at the academic-industry interface. Technovation, 14 (10), 641-655.

MacBryde, J.C. (1997). Commercialisation of university technology: a case in robotics. Technovation, 17 (1), 39-46.

Main, S.A. (1997). Assessing and managing the university technology business incubator: an integrative framework. Journal of Business Venturing, 12 (4), 251-285.

Mian, S.A. (1994). US university-sponsored technology incubators: an overview of management, policies and performance. Technovation, 14 (8), 515-528.

Miller, G. A. (1956). The Magical Number Seven, Plus or Minus Two: Some Limits on our Capacity for Processing Information. Psychological Review, 63, 81-97.

Nazmun, N., Kalle, L., Najmul, H., \& Sergey, V. M. (2006). Success factors for information technology supported international technology transfer: Finding expert consensus. Information \& Management, 43(5), 663-677.

Niina, N. (2003). Looking through a prism - multiple perspective to commitment to international R\&D collaboration. The Journal of High Technology Management Research, 14(1), 135-148.

O'Shea, R.P., Allen, T.J., Chevalier, A., \& Roche, F. (2005). Entrepreneurial orientation, technology transfer and spinoff performance of U.S. universities. Research Policy, 34(7), 994-1009.

Park, B. I. (2011). Knowledge transfer capacity of multinational enterprises and technology acquisition in international joint ventures. International Business Review, 20(1), 75-87.

Parker, D. D., \& Zilberman, D. (1993). University technology transfers: impacts on local and US economies. Contemporary Policy Issues, 11 (2), 87-96.

Pedro, S-A., Angel, L., \& Meroño-C. (2009). Evaluating Internet technologies business effectiveness. Telematics and Informatics, 26(2), 211-221.

Rodrigues, A. G., \& Williams. T.M. (1998). System dynamics in project management: assessing the impacts of client behavior on project performance. Journal of Operational Research Society, 49(1). 2-15.

Siegel, D.S., Waldman, D.A., Atwater, L.E., \& Link, A.N. (2004). Toward a model of the effective transfer of scientific knowledge from academicians to practitioners: qualitative evidence from the commercialization of university technologies. Journal of Engineering and Technology Management, 21(1-2), 115-142.

Shafia, M. A., Shakeri, A. (2010). Introducing a Project Management Framework for Transfer of Technologies. International Journal of Industrial Engineering \& Production Research, 20(4), 177-185.

Sung, T. K. (2009). Technology transfer in the IT industry: A Korean perspective. Technological Forecasting and Social Change, 76(5), 700-708.

Tetsunori, K., \& Kenneth, J. K. (1980). Foreign direct investment, technology transfer and domestic employment effects. Journal of International Economics, 10(1), 1-20.

United Nations. (2006). Taxation and Technology Transfer: Key Issues - Transfer of Technology for Successful Integration into the Global Economy. United Nations Publications.

Wang, Q. F. (1994). System Dynamics, Beijing: Qinghua University Press, pp.11-26.

Warfield, J.N. (1990). A Science of Generic Design: Managing Complexity Through System Design, vol \& II, Intersystems Publication, USA.

Xiaolan, F., Carlo, P., \& Luc, S. (2011). The Role of Foreign Technology and Indigenous Innovation in the Emerging Economies: Technological Change and Catching-up. World Development, 39 (7), 1204-1212. 